\title{
Deep sedation and anaesthesia in complex gastrointestinal endoscopy: a joint position statement endorsed by the British Society of Gastroenterology (BSG), Joint Advisory Group (JAG) and Royal College of Anaesthetists (RCoA)
}

\author{
Reena Sidhu, ${ }^{1}$ David Turnbull, ${ }^{2}$ Mary Newton, ${ }^{3}$ Siwan Thomas-Gibson, ${ }^{4}$ \\ David S Sanders, ${ }^{1}$ Srisha Hebbar, ${ }^{5}$ Rehan J Haidry, ${ }^{6,7}$ Geoff Smith, ${ }^{8}$ \\ George Webster ${ }^{6}$
}

- Additional material is published online only. To view please visit the journal online (http://dx.doi.org/10.1136/ flgastro-2018-101145)

For numbered affiliations see end of article.

\section{Correspondence to}

Dr Reena Sidhu, Academic Unit of Gastroenterology, Royal Hallamshire Hospital, Sheffield Teaching Hospitals NHS Trust, Sheffield S10 2JF, UK; reena. sidhu@sth.nhs.uk

Received 12 November 2018 Revised 5 December 2018 Accepted 16 December 2018

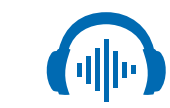

Listen to Podcast fg.bmj.com

\section{Check for updates}

(C) Author(s) (or their employer(s)) 2019. No commercial re-use. See rights and permissions. Published by BMJ.

To cite: Sidhu R, Turnbull D, Newton M, et al. Frontline Gastroenterology

2019:10:141-147.

\section{ABSTRACT}

In the UK, more than 2.5 million endoscopic procedures are carried out each year. Most are performed under conscious sedation with benzodiazepines and opioids administered by the endoscopist. However, in prolonged and complex procedures, this form of sedation may provide inadequate patient comfort or result in oversedation. As a result, this may have a negative impact on procedural success and patient outcome. In addition, there have been safety concerns on the high doses of benzodiazepines and opioids used particularly in prolonged and complex procedures such as endoscopic retrograde cholangiopancreatography. Diagnostic and therapeutic endoscopy has evolved rapidly over the past 5 years with advances in technical skills and equipment allowing interventions and procedural capabilities that are moving closer to minimally invasive endoscopic surgery. It is vital that safe and appropriate sedation practices follow the inevitable expansion of this portfolio to accommodate safe and high-quality clinical outcomes. This position statement outlines the current use of sedation in the UK and highlights the role for anaesthetist-led deep sedation practice with a focus on propofol sedation although the choice of sedative or anaesthetic agent is ultimately the choice of the anaesthetist. It outlines the indication for deep sedation and anaesthesia, patient selection and assessment and procedural details. It considers the setup for a deep sedation and anaesthesia list, including the

\section{Summary points}

- The availability of anaesthetist-led deep sedation and anaesthesia in the UK for complex endoscopy needs to be expanded.

- Adequate preassessment and patient triage is key prior to consideration of deep sedation and anaesthesia.

- Current guidelines dictate that delivery of propofol sedation in the UK must be provided by a qualified anaesthetist supported by a qualified assistant (Operating Department Practitioner or Anaesthetic Nurse).

- A local standard operating procedure needs to be in place to ensure that minimum standards of environment, staffing and delivery of all types of deep sedation and anaesthesia are maintained.

equipment required, the environment, staffing and monitoring requirements. Considerations for different endoscopic procedures in both emergency and elective setting are also detailed. The role for training, audit, compliance and future developments are discussed.

\section{INTRODUCTION}

Endoscopic procedures provide for the diagnosis, screening and treatment of many gastroenterological conditions. In 


\section{Summary points}

- Training in conscious sedation for endoscopy should be included as an essential competency to be achieved at Annual Review of Competency Progression for endoscopy trainees.

- Local training programmes for deep sedation and anaesthesia within endoscopy should be encouraged for anaesthetic trainees.

- Activity and complications must be audited and presented at regular morbidity and mortality meetings.

- There is pressing need for increased collaboration between the Royal College of Anaesthetists, British Society of Gastroenterology and Joint Advisory Group and collaboration between endoscopists, anaesthetists and managerial teams locally to implement deep sedation and anaesthesia provision for complex endoscopy in the UK.

the UK, conscious sedation for endoscopic procedures is usually provided by the endoscopist using shortacting benzodiazepines and opioids or nitrous oxide. ${ }^{1}$ Conscious sedation is defined as being of a level in which patients may perform 'a purposeful response to verbal or light tactile stimulation' and as such do not require the involvement of anaesthetist for healthy patients. $^{2}$

The use of conscious sedation helps to improve the patient experience and procedural success. However, studies have demonstrated that for difficult or prolonged procedures such as device-assisted enteroscopy (DAE), endoscopic retrograde cholangiopancreatography (ERCP) and resection of upper gastrointestinal neoplasia, procedure tolerance remains poor despite inappropriately high doses of sedation. ${ }^{3-5}$ There have also been concerns raised regarding sedation practice in the UK including the potential of oversedation and respiratory compromise in patients, with minimal monitoring for potential apnoea. A 2004 report by the National Confidential Enquiry into Patient Outcome and Death (NCEPOD) reported in patients undergoing therapeutic endoscopy, the sedation given was inappropriate in $14 \%$ of cases, usually through an overdose of benzodiazepines. ${ }^{6}$ The NCEPOD report also highlighted that only $47 \%$ of endoscopists had attended a sedation course. Despite this historical data, the number of sedation courses available for endoscopists remains limited in the UK. ${ }^{7}$ It is not unreasonable to conclude that current UK sedation models are insufficient to manage the increasing complexity of new endoscopic procedures and the increasing comorbidities of patients.

Anaesthetist-led deep sedation or anaesthesia for endoscopy can be achieved using propofol. Propofol is a short-acting intravenous anaesthetic agent that can be used to provide sedation and amnesia. It should be delivered by persons with appropriate training and in the UK, this should be an anaesthetist. Propofol has been shown to provide a better quality of procedural sedation and improve patient satisfaction, procedural outcome and recovery when compared with standard conscious sedation. ${ }^{89}$ However, the use of propofol has been widely debated due to its narrow therapeutic index, the lack of an antidote and risk of cardiorespiratory complications especially in the elderly. Nevertheless, meta-analyses of several randomised controlled trials have reported similar rates of adverse events compared with traditional sedative agents whether administered by anaesthetists or non-anaesthetists. ${ }^{8} 10$ A recent multicentre German study of over 300000 patients undergoing endoscopy, on sedation-related complications (ProSed 2) showed that while overall sedation related complications were generally low $(0.01 \%)$, it was lowest among patients receiving propofol monotherapy. ${ }^{11}$

Providing anaesthetist-led deep sedation and anaesthesia services is a challenge faced by endoscopic units around the world. The barriers to delivery include capacity, funding and staffing. ${ }^{12-14}$ In the UK, propofol-based sedation for endoscopy is provided only by anaesthetists, following the British Society of Gastroenterology (BSG) and Royal College of Anaesthetists (RCoA) guidelines. ${ }^{15}$ The capacity of anaesthetic departments is stretched by demand, and this may be one of the hurdles that will be required to be addressed for the introduction of deep sedation and anaesthesia programmes into endoscopy units in the UK.

This position statement outlines the indications for anaesthetist-led deep sedation and anaesthesia with a focus on propofol sedation for complex gastrointestinal endoscopy. Patient selection, preassessment and procedure specifics are discussed. The statement provides a structure for the delivery of a deep sedation and anaesthesia services.

\section{Selecting patients for anaesthetist-led deep sedation and anaesthesia}

Sedation helps to improve patient tolerability and overall endoscopic experience. It is recommended that a local policy is developed in order that all patients being considered for sedation are adequately assessed at the point of referral.

The objective of preprocedural assessment is patient evaluation and patient optimisation together with consideration of procedural issues and patient consent. In a retrospective study of more than 1 million patients undergoing endoscopy and colonoscopy, higher American Society of Anesthesiologist's (ASA) class were associated with an increased risk of adverse events. ${ }^{16}$ The definition of ASA class is included within online supplementary appendix $1 .{ }^{17}$ Old age, comorbidity and obesity are identified risk factors for cardiopulmonary complications during endoscopy. As obese patients are more prone to airway obstruction, the use of the Berlin 
Table 1 Modified STOP-BANG screening checklist for OSA

\begin{tabular}{l}
\hline Parameters \\
\hline Snoring loudly on regular basis \\
Daytime tiredness \\
Observation of 'gasping for breath in sleep' by others \\
High blood pressure \\
BMl $\geq 35 \mathrm{~kg} / \mathrm{m}^{2}$ \\
Age>50 years \\
Neck details (measured around Adam's apple) \\
Male > 17 in. collar \\
Female > 16 in. collar \\
Gender Male \\
Total 'Yes' score: \\
\hline OSA-Low Risk: Yes to 0-2 questions. \\
OSA-Intermediate Risk: Yes to 3-4 questions. \\
OSA-High Risk: Yes to 5-8 questions. \\
Or Yes to 2 or more of 4 STOP questions+male gender. \\
Or Yes to 2 or more of 4 STOP questions+BMl >35kg/m². \\
Or Yes to 2 or more of 4 STOP questions+neck circumference 17 \\
in./43 cm in male or 16 in./41 cm in female. \\
Adapted from Stop-Bang Questionnaire. \\
Chung F; Anaesthesiology 2008; $108(5): 812-21{ }^{14}$ \\
BMI, body mass index; OSA, obstructive sleep apnoea.
\end{tabular}

or STOP-BANG questionnaires can grade the severity of obstructive sleep apnoea (OSA). ${ }^{12} 13$ It is therefore recommended that all patients being considered for sedation should also be screened for OSA. A modified STOP-BANG screening checklist for OSA prior to consideration of sedation is provided in table $1 .{ }^{14}$ This can be adapted to local policy. The questionnaire would be used as a tool to highlight those at higher risk to the endoscopy team. This would enable the endoscopist to discuss the additional risk of sedation, during the process of consent. The information would also be useful to decide if the procedure could be done unsedated or if the dose of sedation requires titration or a referral for anaesthetic assessment is required.

The choice of sedation is influenced by several factors. A range of procedural and patient-related factors may favour anaesthetist-led deep sedation, including both systemic comorbidities and airway specific considerations (online supplementary appendix 1). Poor tolerance of prior endoscopy under conscious sedation is an important indication for subsequent preference of deep sedation. Procedural factors such as duration of the procedure are an important consideration. The ProSed2 study showed that risks of complications were linearly associated with duration of procedure with the OR for complications increased by 1.8 for Procedures $<10 \mathrm{~min}$ in contrast to 7.9 for Procedures $>1$ hour. ${ }^{11}$ Similarly, therapeutic procedures are associated with increased risk. Comparison of procedure subtypes in the same study showed increased risk for ERCP, oesophagogastroduodenoscopy (particularly in the emergency setting such as GI bleeding) and enteroscopy compared with that of diagnostic
Table 2 Procedures for Consideration of anaesthetist led deep sedation/anaesthesia list

\begin{tabular}{ll}
\hline Procedure type & Procedure detail \\
\hline Upper gastrointestinal & $\begin{array}{l}\text { Upper Gl polypectomy/resection of neoplasia } \\
\text { Endoscopic bariatric surgery } \\
\text { Large variceal bleed } \\
\text { Foreign body retrieval } \\
\text { Other prolonged/therapeutic } \\
\text { procedures }>60 \text { min }\end{array}$ \\
Pancreas and hepatobiliary & $\begin{array}{l}\text { Therapeutic endoscopic ultrasound } \\
\text { Endoscopic retrograde } \\
\text { cholangiopancreatography } \\
\text { Pancreatic fluid collection drainage }\end{array}$ \\
& $\begin{array}{l}\text { Device assisted enteroscopy including double } \\
\text { balloon, single balloon or spiral enteroscopy }\end{array}$ \\
Lower gastrointestinal & $\begin{array}{l}\text { Complex polypectomy } \\
\text { Other prolonged/therapeutic } \\
\text { procedures }>60 \text { min }\end{array}$ \\
\hline
\end{tabular}

endoscopic ultrasound (EUS) and colonoscopy. ${ }^{11}$ Hence, deep sedation should be considered for (but not limited to) ERCP, small bowel enteroscopy, therapeutic EUS, complex polypectomy and any prolonged therapeutic procedure (table 2). Multidisciplinary team meetings are recommended when planning these procedures.

The use of deep sedation also extends to emergency procedures. A cohort of these patients may also have an elevated physiological score, such as the National Early Warning score (NEWS2) on routine observations and may require optimisation prior to the procedure. ${ }^{18}$ For those at risk of aspiration, such as the presence of significant gastrointestinal bleeding or recent oral intake, a balance of procedural delay or a general anaesthetic with tracheal intubation should be considered.

\section{When should general anaesthesia be considered instead of deep sedation?}

Decisions concerning deep sedation or general anaesthesia can be made as part of the anaesthetic preassessment process and will be influenced by local protocols and experience. Patients who will require deep sedation or anaesthesia should be preassessed in a timely fashion (an example of a simplified preassessment form is provided in online supplementary appendix 1), ideally in the hospital's Pre-assessment Clinic, and those with significant risk factors reviewed by the anaesthetic lead. ${ }^{1920}$ In patients with a difficult airway, it is imperative that sufficient time is given for careful anaesthetic evaluation. ${ }^{21}$

A study of $>300000$ propofol endoscopies indicated a very low incidence of complications attributable to aspiration. ${ }^{12}$ However, tracheal intubation may be indicated where large amounts of fluid are anticipated in the oesophagus or stomach (eg, variceal bleed, gastric outlet obstruction or foreign body retrieval) or during 
Table 3 Financial considerations for an anaesthetist-led deep sedation/anaesthesia list

\begin{tabular}{ll}
\hline $\begin{array}{l}\text { Capital outlay (non- } \\
\text { recurrent) }\end{array}$ & $\begin{array}{l}\text { Target-controlled infusion pump } \\
\text { Anaesthetic machine with monitoring } \\
\text { High flow nasal oxygen delivery-recommended } \\
\text { Awareness monitor (bispectral index) } \\
\text { recommended }\end{array}$ \\
Additional consumables & $\begin{array}{l}\text { Propofol and other anaesthetic agents } \\
\text { Triple lumen IV catheters }\end{array}$ \\
Additional staffing & $\begin{array}{l}\text { Consultant Anaesthetist } \\
\text { Operating Department Practitioner (ODP) or } \\
\text { Anaesthetic Nurse }\end{array}$ \\
\hline
\end{tabular}

the procedure (eg, transgastric endoscopic drainage of pancreatic fluid collection.

Delivering a deep sedation and anaesthesia service and a standard operating procedure (SOP)

Implementing a sustainable and flexible deep sedation and anaesthesia service requires the formal appraisal and subsequent allocation of resources at a local level. This would require submission of a business case to resource the added cost of involvement of the anaesthetists. While formal cost saving has not been reported in the non-theatre setting, practice efficiency improvements with propofol sedation have been observed. ${ }^{22} 23$ Table 3 tabulates an example of financial considerations to be made for setting up a deep sedation and anaesthesia service, in a non-theatre environment.

In addition to national guidelines, a local protocol and SOP that represent service requirements are encouraged, to facilitate implementation of deep sedation and anaesthesia services within the endoscopy setting. There should be a lead consultant anaesthetist and consultant endoscopist responsible for the development of the service. Morbidity and mortality meetings should be held, and an audit of complications should be regularly reviewed. This recommendation is also supported by the Joint Advisory Group (JAG) as part of the global rating scale (GRS) requirement from the Improve Safety and Reducing Error in Endoscopy (ISREE) strategy. ${ }^{24}$

\section{STAFFING}

Provision must be made for appropriate staffing in the endoscopy suite and recovery area. A minimum of two qualified nurses are required for the endoscopic procedure and the recovery area. It is desirable that at least one of the nurses should be a certified intermediate or advanced life support (ILS or ALS) provider. The RCoA recommends the presence of an operating department practitioner (ODP) or Anaesthetic Nurse to assist the anaesthetist. ${ }^{25}$ Patients should be given similar advice to those receiving conscious standard sedation at discharge by the Recovery Nurse and accompanied home by a responsible adult.
Table 4 Room checklist for an anaesthetist led deep sedation/ anaesthesia list

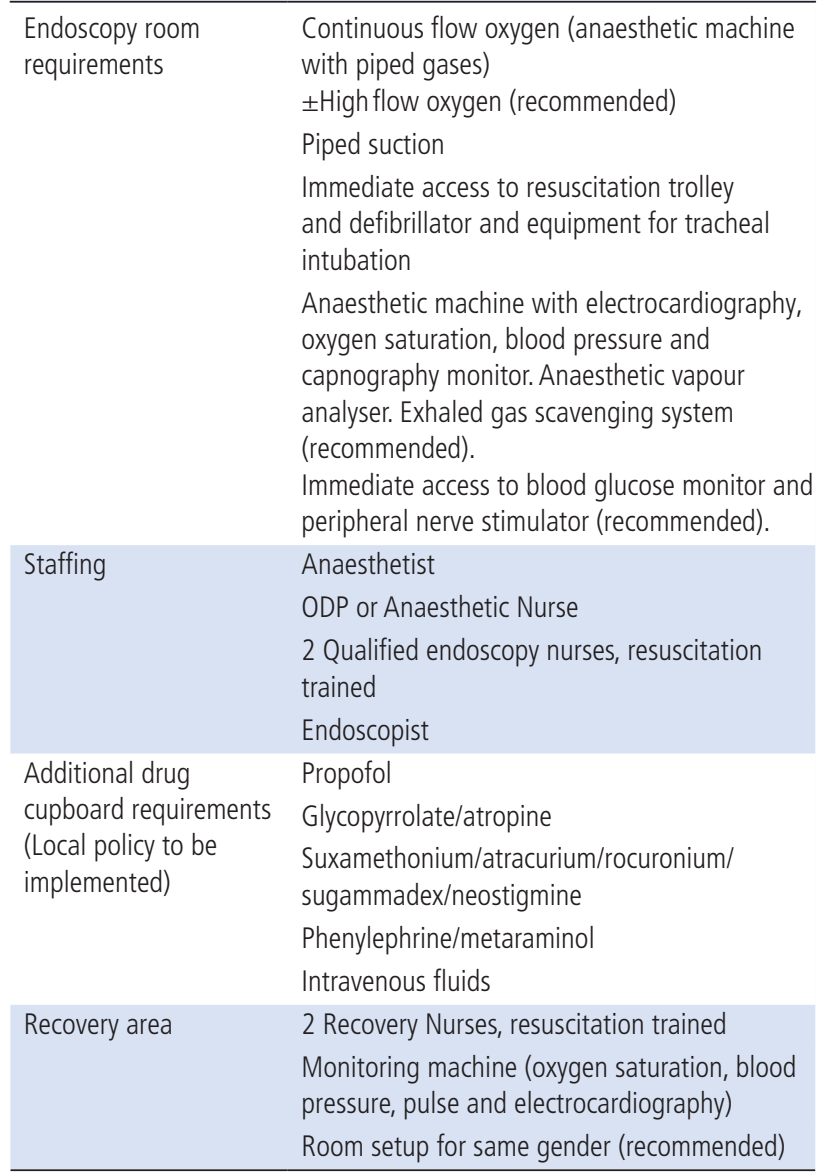

ODP, Operating Department Practitioner.

\section{ENVIRONMENT}

The endoscopy rooms where deep sedation or anaesthesia is to be delivered should be large enough to accommodate equipment and personnel, with enough space to move about safely and to enable easy access to the patient at all times. The room should have full facilities for resuscitation including immediate access to a defibrillator, continuous delivery of piped oxygen and suction, airway devices and a means of providing ventilation. A room checklist for deep sedation is provided in table 4 . The endoscopy specific WHO safety checklist should be mandatory periprocedure. In addition, the provision of an anaesthetic machine within the endoscopy room is highly recommended (table 3-financial consideration of setting up a deep sedation or anaesthesia list). Within the endoscopy room, it is vital that the drug cupboard is regularly stocked for the provision of propofol or general anaesthesia and in anticipation of the management of any complications related to this (table 4).

\section{Quality assessment and audit parameters}

For units to deliver deep sedation and anaesthesia, compliance with the JAG regulations will need to be adhered to. ${ }^{26}$ The basic requirement of JAG stipulates 
that all patients being considered for deep sedation and anaesthesia are appropriately preassessed and consented and that there is a service sedation lead responsible for this deep sedation service, mirroring the SOP above. Consent should discuss complications of the procedure itself and those related to deep sedation and anaesthesia including accidental awareness. ${ }^{27}$ Complications resulting from the administration of deep sedation or anaesthesia or the administration of a reversal agent for conscious sedation (eg, flumazenil or naloxone) must result in a 'incident reporting system' or DATIX submission and an appropriate significant incident investigation carried out where appropriate. ${ }^{24}$ In 2018, the JAG launched the ISREE strategy to improve safety and reduce errors. A significant area of focus within this strategy will be to improve training in and delivery of conscious and deep sedation within endoscopy. ${ }^{28}$

The recent development of the National Endoscopy Database (NED) in the UK allows audit of sedation practice and comfort scores of patients undergoing endoscopy at a national level. ${ }^{29}$ Data capture from NED over the next few years on conscious and deep sedation or anaesthesia use in different patient groups and procedures will allow robust audit to understand trends and unmet needs for services to develop and improve.

\section{Training}

Formal training in the UK of endoscopists and endoscopy teams in the management and delivery of sedation has historically been limited and patchy. The Academy of Medical Royal Colleges (AoMRC) in 2013 considered that the single most common recurring theme following sedation-related avoidable morbidity and mortality is the lack of formal training in the appropriate administration of sedative drugs and prompt recognition and treatment of sedation-related complications. ${ }^{30}$ This AoMRC document recommends that there must be formal accredited competency-based training in defined methods of sedation. Key areas of training, pertinent to safe sedation include preassessment, information and consent, fasting, the WHO checklist, choice of drug and titration to effect, monitoring and the use of supplementary oxygen and recovery facilities. Training must also include teaching on the prompt recognition and management of sedation-related complications and use of relevant antagonists. Endoscopy trainees expected to use conscious sedation techniques within their sphere of practice on obtaining their Certificate of Completion of Training 'must demonstrate acquisition of the necessary competencies at Annual Review of Competency Progression or through an equivalent process, ${ }^{30}$

The lack of training on conscious sedation for endoscopists in the UK is being addressed. This has recently been adopted as a focus by JAG within the ISREE strategy. Several competency-based courses on the provision of safe conscious sedation are also being developed in the UK. One is the National Safe Sedation (NSS) course which was developed in collaboration with the Royal College of Anaesthetists. It addresses all the recommendations in the AoMRC document and teaches appropriate airway skills. Following a successful pilot, the NSS course will be accessible in early 2019 .

The delivery of deep sedation and anaesthesia in the UK currently remains within the remit of anaesthetists. The delivery of deep sedation within the theatre and non-theatre environment is incorporated into the anaesthetic core and advanced curriculae. ${ }^{31} 32$ A sedation training programme should be developed at a local level for anaesthetic trainees by the anaesthetic and endoscopy sedation leads to ensure familiarity with the endoscopy environment and the procedures performed there, focusing on particular challenges such as the shared airway, aspiration risk and working in a non-theatre environment.

\section{DISCUSSION}

For decades, sedation for endoscopy has almost exclusively been given by the endoscopist. With an increasing demand for complex diagnostic and therapeutic procedures in patients with greater comorbidities, alternatives to the benzodiazepine/ opioid conscious sedation model are required. ${ }^{33} 34$ There is also a cost to having little or no alternative to conscious sedation. As a means to ensure a comfortable patient (and so allowing the procedure to be completed), the national BSG audit reported that $33 \%$ of patients undergoing ERCP received more than $5.5 \mathrm{mg}$ of midazolam. As a result, $8 \%$ required a reversal with flumazenil and/or naloxone. ${ }^{35}$ Conversely, the inability to safely provide sufficient sedation using conscious sedation results in $40 \%$ of patients reporting pain or discomfort during ERCP. ${ }^{4}$ Intolerance of sedation contributes to more than $30 \%$ of failed ERCPs performed under conscious sedation. ${ }^{46}$ Tolerability of double balloon enteroscopy has also been reported to be poor despite high doses of sedation given. ${ }^{5}$ As a means to complete a required therapeutic procedure, how often is 'conscious' sedation given to a deeper level of sedation, which should involve an anaesthetist?

Change is occurring, such that there is perhaps no more divergent area of present UK endoscopic practice than the predictable availability of anaesthetist-led deep sedation for endoscopy (with propofol or general anaesthesia), ranging for ERCP from $0 \%$ to $100 \%$ in individual centres. Despite the definite merits of deep sedation and anaesthesia for complex endoscopy, there are challenges to its introduction. Many countries have provided guidance for deep sedation using propofol, through the publication of position statements, guidelines and the development of training programmes. ${ }^{37}$ Non-anaesthetist 
administered propofol (NAAP) services have been reported to be safe and effective, but the current UK position is that propofol administration should be the responsibility of a dedicated and appropriately trained anaesthetist. ${ }^{38-40}$

There is pressing need for increased collaboration between the RCoA, BSG and JAG and collaboration between endoscopists, anaesthetists and managerial teams locally to implement deep sedation and anaesthesia provision for complex endoscopy in the UK. We believe that all endoscopy services require the regular and reliable provision of anaesthetist-led deep sedation and anaesthesia services, with the frequency dependent on procedural and case complexity.

This requires changes in working practice covering the whole patient journey, including preassessment, patient triage, flexible and responsive sedation options and recovery. The days should be over in which clinicians and patients are faced with an unacceptable choice between prolonged delays for appropriate sedation to be available for their endoscopy or proceeding with endoscopist-administered conscious sedation despite well recognised factors predicting increased risk or poor patient outcome.

\section{CONCLUSION}

The requirement for anaesthetist-led deep sedation and anaesthesia services in the UK for complex gastrointestinal endoscopy is increasing. This position statement highlights the challenges faced and also provides a framework for the delivery of this service for endoscopists across the UK.

\footnotetext{
Author affiliations

${ }^{1}$ Academic Unit of Gastroenterology, Royal Hallamshire Hospital, Sheffield Teaching Hospitals NHS Trust, Sheffield, UK

${ }^{2}$ Department of Anaesthesia, Royal Hallamshire Hospital, Sheffield Teaching Hospitals NHS Trust, Sheffield, UK

${ }^{3}$ Department of Anaesthesia, The National Hospital for Neurology and Neurosurgery, UCLH NHS Foundation Trust, London, UK

${ }^{4}$ Imperial College, Chair Joint Advisory Group Gastrointestinal Endoscopy, St Mark's Hospital, Harrow, UK

${ }^{5}$ Department of Gastroenterology, Stoke University Hospital University, Hospitals of North Midlands NHS Trust, Sheffield, UK

${ }^{6}$ Department of Gastroenterology, University College London Hospital NHS Foundation Trust, London, UK

${ }^{7}$ Division of Surgery \& Interventional Science, University College London (UCL), London, UK

${ }^{8}$ Gastroenterology, Imperial College Healthcare NHS Trust, London, UK
}

Contributors GW proposed this position statement on behalf of the BSG Endoscopy Committee, contributed in writing the content of the manuscript, reviewed the revisions and approved the final version. RS structured the manuscript, wrote the initial draft, made all the revisions and submitted the manuscript. DT assisted with the initial draft and all subsequent revisions and final draft and did referencing for the document. MN, ST-G and DSS contributed in writing the content of the manuscript and critically appraised subsequent versions and approved the final version. GS and SH critically appraised all versions and approved the final version. $\mathrm{RJH}$ contributed in writing the content of the manuscript and critically appraised subsequent versions and approved the final version. RS and GW are the guarantors of the manuscript.
Funding The authors have not declared a specific grant for this research from any funding agency in the public, commercial or not-for-profit sectors.

Competing interests $\mathrm{MN}$ is the director of the National Safe Sedation course. ST-G: Olympus: honoraria and equipment loans Fujinon; Pentax- educational funds and equipment loans SH: Educational funds from Aquilant Endoscopy. GW: Advisory board and educational funds: Olympus, Boston Scientific, Cook Medical, Pentax Medical. RS, DT, DSS, GS and $\mathrm{RJH}$ have no competing interests.

Patient consent Not required.

Provenance and peer review Not commissioned; externally peer reviewed.

Author note This position statement was reviewed and endorsed by the British Society of Gastroenterology (BSG), Joint Advisory Group (JAG) and Royal College of Anaesthetists (RcoA) Nov 2018.

\section{REFERENCES}

1 Triantafillidis JK, Merikas E, Nikolakis D, et al. Sedation in gastrointestinal endoscopy: current issues. World J Gastroenterol 2013;19:463-81.

2 Early DS, Lightdale JR, Vargo JJ, et al. Guidelines for sedation and anesthesia in GI endoscopy. Gastrointest Endosc 2018;87:327-37.

3 Elphick DA, Donnelly MT, Smith KS, et al. Factors associated with abdominal discomfort during colonoscopy: a prospective analysis. Eur J Gastroenterol Hepatol 2009;21:1076-82.

4 Jeurnink SM, Steyerberg E, Kuipers E, et al. The burden of endoscopic retrograde cholangiopancreatography (ERCP) performed with the patient under conscious sedation. Surg Endosc 2012;26:2213-9.

5 Irvine AJ, Sanders DS, Hopper A, et al. How does tolerability of double balloon enteroscopy compare to other forms of endoscopy? Frontline Gastroenterol 2016;7:41-6.

6 Cullinane M, Gray AJG, Hargraves C, et al. The 2004 report of the National Confidential Enquiry into Patient Outcome and Death. London: National Confidential Enquiry into Patient Outcome and Death, 2004:1-20.

7 Mohanaruban A, Bryce K, Radhakrishnan A, et al. Safe sedation practices among gastroenterology registrars: do we need more training? Frontline Gastroenterol 2015;6:223-8.

8 McQuaid KR, Laine L. A systematic review and meta-analysis of randomized, controlled trials of moderate sedation for routine endoscopic procedures. Gastrointest Endosc 2008;67:910-23.

9 Smith I, Durkin D, Lau KW, et al. Establishing an anaesthetistdelivered propofol sedation service for advanced endoscopic procedures: implementing the RCA/BSG guidelines. Frontline Gastroenterol 2018;9:185-91.

10 Singh H, Poluha W, Cheung M, et al. Propofol for sedation during colonoscopy. Cochrane Database Syst Rev 2008:CD006268.

11 Behrens A, Kreuzmayr A, Manner H, et al. Acute sedationassociated complications in GI endoscopy (ProSed 2 Study): results from the prospective multicentre electronic registry of sedation-associated complications. Gut 2018:gutjnl-2015-311037.

12 Netzer NC, Stoohs RA, Netzer CM, et al. Using the Berlin Questionnaire to identify patients at risk for the sleep apnea syndrome. Ann Intern Med 1999;131:485-91.

13 Corso RM, Piraccini E, Agnoletti V, et al. Clinical use of the STOP-BANG questionnaire in patients undergoing sedation for endoscopic procedures. Minerva Anestesiol 2012;78:109-10.

14 Chung F, Yegneswaran B, Liao P, et al. STOP questionnaire: a tool to screen patients for obstructive sleep apnea. Anesthesiology 2008;108:812-21.

15 Tomlinson A, Green J, Cairns S, et al. Guidance for the use of propofol sedation for adult patients undergoing Endoscopic 
Retrograde Cholangiopancreatography (ERCP) and other complex upper GI endoscopic procedures: Royal College of Anaesthetists and British Society of Gastroenterology, 2014:18.

16 Enestvedt BK, Eisen GM, Holub J, et al. Is the American Society of Anesthesiologists classification useful in risk stratification for endoscopic procedures? Gastrointest Endosc 2013;77:464-71.

17 Dripps RD. New classification of physical status. Anesthesiology 1963;24:111.

18 Williams B, Alberti G, Ball C, et al. National Early Warning score (NEWS) 2: standardising the assessment of acute-illness severity in the NHS: Royal College of Physicians, 2017:1-77.

19 National Institute for Health and Care Excellence. Routine preoperative tests for elective surgery: National Institute for Health and Care Excellence, 2016:1-17.

20 Anaesthetic Association of Great Britain and Ireland. Preoperative Assessment and Patient Preparation: The Role of the Anaesthetist: Aagbi Safety Guideline, 2010:1-37.

21 American Society of Anesthesiologists Task Force on Sedation and Analgesia by Non-Anesthesiologists. Practice guidelines for sedation and analgesia by non-anesthesiologists. Anesthesiology 2002;96:1004-17.

22 Vargo JJ, Bramley T, Meyer K, et al. Practice efficiency and economics: the case for rapid recovery sedation agents for colonoscopy in a screening population. J Clin Gastroenterol 2007;41:591-8.

23 Helmers RA, Dilling JA, Chaffee CR, et al. Overall cost comparison of gastrointestinal endoscopic procedures with endoscopist- or anesthesia-supported sedation by activity-based costing techniques. Mayo Clin Proc Innov Qual Outcomes 2017;1:234-41.

24 Thomas-Gibson S, Matharoo M, Siau K, et al. PTH-044 Improving safety and reducing error in endoscopy (ISREE) - a jag initiative. Gut 2018;67:A34-A.

25 Jackson I. Raising the Standard: a compendium of audit recipes (3rd edition) 2012: Anaesthesia and sedation outside theatres:1-15.

26 Summary guide to quality and safety indicators. Joint Advisory Group on gastrointestinal endoscopy (JAG). 2016-.

27 Jonker WR, Hanumanthiah D, O'Sullivan EP, et al. A national survey (NAP5-Ireland baseline) to estimate an annual incidence of accidental awareness during general anaesthesia in Ireland. Anaesthesia 2014;69:969-76.
28 Thomas-Gibson S. Joint advisory group on gi endoscopy. 2018.

29 . The National Endoscopy Database (NED) ProjectBritish society of gastroenterolog, joint advisory group on gi endoscopy. 2017.

30 Sneyd R, Benger J, Blayney S, et al. Safe Sedation Practice for Healthcare Procedures. Standards and Guidance: Academy of Medical Royal Colleges, 2013.

31 Royal College of Anaesthetists. CCT in anaesthetics - basic level training (annex B). 2010:1-99.

32 Royal College of Anaesthetists. CCT in anaesthetics - advanced level training. 2010:1-68.

33 Riphaus A, Stergiou N, Wehrmann T. Sedation with propofol for routine ERCP in high-risk octogenarians: a randomized, controlled study. Am J Gastroenterol 2005;100:1957-63.

34 Sethi S, Wadhwa V, Thaker A, et al. Propofol versus traditional sedative agents for advanced endoscopic procedures: a metaanalysis. Dig Endosc 2014;26:515-24.

35 Williams EJ, Taylor S, Fairclough P, et al. Are we meeting the standards set for endoscopy? results of a large-scale prospective survey of endoscopic retrograde cholangio-pancreatograph practice. Gut 2007;56:821-9.

36 Church NI, Seward EW, Pereira SP, et al. Success of repeat ercp following initial therapeutic failure. Gastrointest Endosc 2006;63:AB293.

37 Dumonceau JM, Riphaus A, Schreiber F, et al. Nonanesthesiologist administration of propofol for gastrointestinal endoscopy: european society of gastrointestinal endoscopy, european society of gastroenterology and endoscopy nurses and associates guideline--Updated June 2015. Endoscopy 2015;47:1175-89.

38 Pelosi P. Retraction of endorsement: European Society of Gastrointestinal Endoscopy, European Society of Gastroenterology and Endoscopy Nurses and Associates and the European Society of Anaesthesiology Guideline-non-anaesthesiologist administration of propofol for gastrointestinal endoscopy. Eur J Anaesthesiol 2012;29:208.

39 British Society of Gastroenterology. Guidance for the use of propofol sedation for adult patients undergoing Endoscopic Retrograde Cholangiopancreatography (ERCP) and other complex upper GI endoscopic procedures. 2011:1-6.

40 Rex DK, Overley C, Kinser K, et al. Safety of propofol administered by registered nurses with gastroenterologist supervision in 2000 endoscopic cases. Am J Gastroenterol 2002;97:1159-63. 